\section{Change to U-100 insulin does not appear to affect insulin absorption}

On 1 March a two year programme began in the United Kingdom of phased transfer of all diabetics requiring insulin to insulin in a strength of 100 units $/ \mathrm{ml}$. Factors affecting the absorption of insulin from subcutaneous tissues include site of injection, ${ }^{1}$ exercise, ${ }^{2}$ dose ${ }^{3}$ strength of the insulin, volume, and the patient's age. ${ }^{4}$ We examined the effect of giving identical doses of soluble insulin in strengths of U-40 (40 units $/ \mathrm{ml}$ ) and U-100 (100 units $/ \mathrm{ml})$.

\section{Patients, methods, and results}

Eight diabetic children aged 7-15 years were given on two successive mornings in hospital exactly comparable subcutaneous injections into the thigh of either U-40 or U-100 neutral insulin (Actrapid MC) followed by identical breakfasts and exercise. The previous evening they had received their normal dose of a combination of soluble and intermediate acting insulins. To avoid rapid hypoglycaemia the dose of insulin given was roughly two thirds of the usual total morning dose, the longer acting insulin being omitted. In four cases U-40 was given on the first morning followed by U-100 on the second morning, and in the other four cases the order was reversed. Blood glucose was measured half hourly for up to four hours after breakfast and the serum insulin concentration estimated on three occasions in each child. Samples were taken through an indwelling butterfly needle to avoid repeated venepuncture. Approval of the ethical committee was obtained.

Two patients were excluded from the study because of practical difficulties. Free insulin concentrations rose from a mean basal value of $30.5+$ SD 23.4 $\mathrm{mU} / 1$ in the subjects given $\mathrm{U}-40$ insulin to a peak at 90 minutes of $58 \cdot 8+28.3$ $\mathrm{mU} / \mathrm{l}$. Patients' response to the same dose of $\mathrm{U}-100$ insulin was a rise from a mean of $22 \cdot 3: 14 \cdot 4 \mathrm{mU} / 1$ to $49 \cdot 0+16 \cdot 1 \mathrm{mU} / \mathrm{l}$. Thus the increment in free insulin values was a mean of $28 \cdot 3 \pm 14 \cdot 0 \mathrm{mU} / \mathrm{l}$ after $\mathrm{U}-40$ insulin and $26 \cdot 7+24 \cdot 0 \mathrm{mU} / 1$ after $\mathrm{U}-100$ insulin.

The closely similar increments in free insulin concentrations after injections of U-40 and U-100 were reflected in the parallel rise and fall of the blood glucose concentrations (figure). The figure was constructed from the mean blood glucose values of six patients at specific times after the insulin injections. Thus the concentrations rose from a mean of $8.1 \mathrm{mmol} / 1(146 \mathrm{mg} / 100 \mathrm{ml})$ to a peak of $14.6 \mathrm{mmol} / 1(263 \mathrm{mg} / 100 \mathrm{ml})$ at 90 minutes after U-40 insulin. The comparative figures for U-100 insulin showed a rise from $9.6 \mathrm{mmol} / \mathrm{l}$ $(173 \mathrm{mg} / 100 \mathrm{ml})$ to a peak of $16.0 \mathrm{mmol} / 1(288 \mathrm{mg} / 100 \mathrm{ml})$ at 90 minutes. The fasting blood glucose value on the second morning in hospital tended to be higher than on the first morning, which explained the discrepancy in fasting values between the two curves. Large increments in blood glucose values reflected the use of suboptimal doses of soluble insulin in this study.

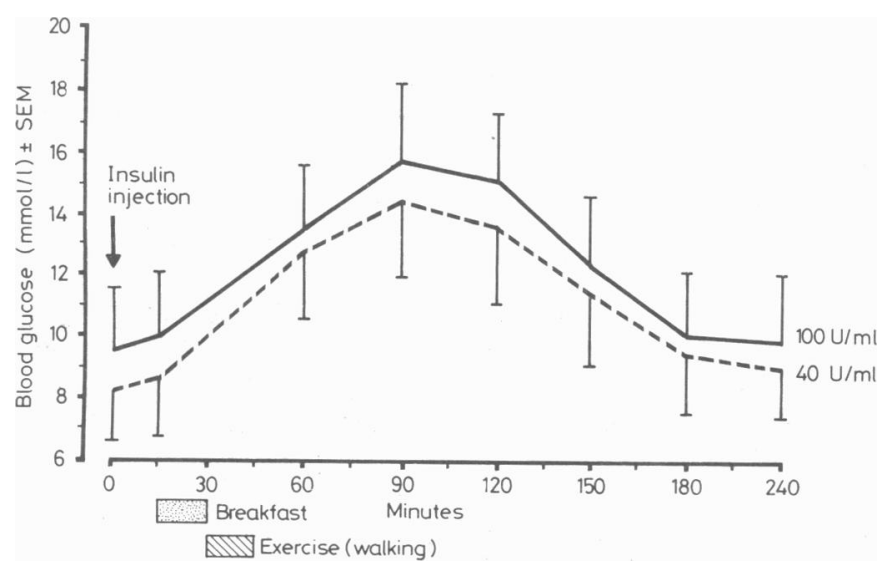

Mean and range of changes in blood glucose concentrations in six insulin dependent diabetics after suboptimal doses of U-40 and U-100 insulin.

Conversion: $S I$ to traditional units-Blood glucose: $1 \mathrm{mmol} / 1 \approx 18 \mathrm{mg} / 100$ $\mathrm{ml}$.

\section{Comment}

Binder ${ }^{4}$ showed that absorption of insulin is decreased by increasing concentration and increasing volume of injected insulin. In changing from U-40 to U-100 insulin in identical doses these two factors appear to be balanced-that is, we are giving a smaller volume of an insulin of greater strength. These variations in absorption may be mediated by effects on subcutaneous blood flow, insulin having a vasoconstrictive effect. ${ }^{5}$

This study showed no apparent practical difference between the absorption and effects of U-40 and U-100 insulin when given as carefully controlled single injections. Further repeated dose studies during field trials with the new glass U-100 syringes confirmed this.

From these findings the change to $U-100$ insulin should present few problems from the standpoint of insulin action. Nevertheless, the use of glass syringes, which have a significant dead space, the difficulties of measuring very small doses of highly concentrated insulin, and the variable quality of injection techniques and injection sites are other factors which will require consideration when patients (particularly the very young and very old) change over from U-40 to U-100 insulin.

We thank Mrs C Owens, of the department of biochemistry at Bristol Maternity Hospital, for the insulin measurements.

${ }^{1}$ Koivisto VA, Felig P. Alterations in insulin absorption and in blood glucose control associated with varying insulin injection sites in diabetic patients. Ann Intern Med 1980;92:59-61.

${ }^{2}$ Koivisto VA, Felig P. Effects of leg exercise on insulin absorption in diabetic patients. $N$ Engl f Med 1978;298:77-83.

${ }^{3}$ Lauritzen T, Pramming S, Gale EAM, Deckert T, Binder C. Absorption of isophane (NPH) insulin and its clinical implications. $\mathrm{Br}$ Med $\mathcal{F} 1982$; 285: 159-62.

4 Binder C. Absorption of injected insulin. Copenhagen: Munksgaard, 1969.

5 Williams G, Clark AJL, Cook E, Bowcock S, Pickup JC, Keen H. Local changes in subcutaneous blood flow around insulin injection sites measured by photoelectric plethysmography. Diabetologia 1981 ;21 :516. (Abstract.)

(Accepted 20 January 1983)

Paediatric Department, Leicester General Hospital, Leicester LE5 4PW

P G F SWIFT, MA, MRCP, consultant paediatrician

J D KENNEDY, MB, MRCP, paediatric registrar

Novo Laboratories Limited, Basingstoke, Hampshire

L S GERLIS, MA, MRCP, medical director

Correspondence to: Dr P G F Swift.

W 